\title{
Кто и почему ищет государственной поддержки в новой России?'
}

\author{
В.А. АНИКИН ${ }^{*}$, Ю.П. ЛЕЖНИНА**, С.В. МАРЕЕВА***, Е.Д. СЛОБОДЕНЮК****
}

\begin{abstract}
*Василий Александрович Аникин - кандидат экономических наук, $\mathrm{PhD}$ (Sociology), доцент, старший научный сотрудник, Национальный исследовательский университет «Высшая школа экономики». Адрес: 101000, Москва, Мясницкая ул., д. 20; ведущий научный сотрудник, Институт социологии ФНИСЦ РАН. Адрес: 117218, Москва, ул. Кржижановского, д. 24/35, к. 5. E-mail: vanikin@hse.ru

**Юлия Павловна Лежнина - кандидат социологических наук, доцент, старший научный сотрудник, Национальный исследовательский университет «Высшая школа экономики». Адрес: 101000, Москва, Мясницкая ул., д. 20; старший научный сотрудник, Институт социологии ФНИСЦ РАН. Адрес: 117218 , Москва, ул. Кржижановского, д. 24/35, к. 5. E-mail: jlezhnina@hse.ru

***Светлана Владимировна Мареева - кандидат социологических наук, заведующий центром стратификационных исследований, Национальный исследовательский университет «Высшая школа экономики». Адрес: 101000, Москва, Мясницкая ул., д. 20; ведущий научный сотрудник, Институт социологии ФНИСЦ РАН. Адрес: 117218 , Москва, ул. Кржижановского, д. 24/35, к. 5. E-mail: smareeva@hse.ru

****Екатерина Дмитриевна Слободенюк - кандидат социологических наук, доцент, научный сотрудник, Национальный исследовательский университет «Высшая школа экономики». Адрес: 101000, Москва, Мясницкая ул., д. 20; научный сотрудник, Институт социологии ФНИСЦ РАН. Адрес: 117218, Москва, ул. Кржижановского, д. 24/35, к. 5. E-mail: eslobodenyuk@hse.ru
\end{abstract}

Цитирование: Аникин В.А., Лежнина Ю.П., Мареева С.В., Слободенюк Е.Д. (2020) Кто и почему ищет государственной поддержки в новой России? // Мир России. Т. 29. № 1. C. 31-52. DOI: 10.17323/1811-038X-2020-29-1-31-52

В статье анализируется вопрос о том, какова природа запросов россиян на содействие государства в сферах занятости, сочиального инвестирования и материальной поддержки. На основании современной теории изучения общественного мнения, социальной стратификаџии и рынка труда был протестирован вклад четырех механизмов: (а) демографических особенностей населения, (б) доходов домохозяйств и располагаемых ресурсов, в том числе нематериальных активов, включая человеческий и социальный капитал,

\footnotetext{
1 Исследование осуществлено в рамках Программы фундаментальных исследований НИУ ВШЭ в 2019 г. Авторы благодарят Институт социологии Федерального научно-исследовательского центра Российской академии наук (ФНИСЦ РАН) за возможность использовать социологические данные Всероссийского мониторинга, созданные при финансовой поддержке Российского научного фонда.
} 
(в) индивидуальных интересов, а также (2) социально-психологических установок. По итогам эконометрического анализа, проведенного на базе Всероссийского мониторинга ФНИСЦ РАН 2018 года, авторы пришли к выводу, что запросы на содействие государства имеют сложную природу и существует всего лишь один универсальный фактор - доход, однако его влияние носит неоднозначный характер. Данные показывают, что с повышением дохода вероятность запроса на помощь государства в области материальной поддержки только возрастает, что корреспондирует с недавними выводами зарубежных исследователей об «альтруизме богатых». Тем не менее с ростом дохода она снижается только у россиян, которые не испытывают нужды в помощи государства в сфере занятости. Таким образом, сочиальная политика, построенная исключительно на монетарных инструментах, без необходимых институциональных мер на рынке труда обречена на провал с точки зрения реализации гетерогенных потребностей и интересов населения.

Ключевые слова: социальная политика, государство всеобщего благосостояния, социальное инвестирование, политика занятости, материальная поддержка, новая Россия

В настоящее время модель государства всеобщего благосостояния, основанная на активной роли государства в социальной сфере, находится в глубоком кризисе, делаются неоднократные попытки ее пересмотреть и трансформировать [Chung, TaylorGooby, Leruth 2018]. Схожие процессы происходят и в России, в результате чего правительство РФ все больше «торгует неопределенностью» [Greene 2018], разрушая «неформальный договор с обществом» [Тихонова 2013]2. Социетальный порядок в России исторически строился на поддержке населением неоэтакратической модели государства, предполагающей доминирование интересов макрообщности над интересами конкретной личности и, как следствие, ярко выраженных запросах к проактивной политике государства во всех ключевых сферах общества [Авраамова 2006; Аникин 2016; Мареева 2018; Петухов 2011; Гориков, Тихонова 2008; Тихонова 2011; Тихонова 2018; Шкаратан (2) 2009]. В этой связи изучение природы запросов населения к государству и его роли в обществе является крайне своевременной задачей, особенно в условиях нарастания запроса наших граждан на политические изменения ${ }^{3}$.

Однако проблема состоит в том, что фокусом подобных исследований в индустриально развитых странах обычно выступают нормативные запросы населения к государству, то есть через призму социальных установок граждан, а не их реальных нужд (см., например: [Cappelen, Cappelen, Kuhnle, Tungodden 2018; Garritzmann, Busemeyer, Neimanns 2018; Gingrich, Ansell 2012; Roosma, van Oorschot, Gelissen 2014]). Предмет же данного исследования составляют запросы, отражающие в том числе интересы и реальные потребности россиян, а не только их нормативные представления о роли государства в обществе в целом.

2 Следует отметить, что некоторые сторонники цивилизационного подхода считают, что применительно к российскому социуму говорить о каком-либо социальном контракте неуместно в принципе, поскольку «Россия не имела “договорных" институтов, аналогичных западному городскому самоуправлению и вассалитету» [Липкин 2012, с. 50]. Вместо этого в ней утвердилась «приказная» система общественных отношений, в рамках которой законы «закрепляют не права, а компетенции и наказания за невыполнение приказа» [Липкин 2012, с. 43].

3 Данные Всероссийского мониторинга ФНИСЦ РАН, октябрь 2018 г. Более подробно см.: «Коммерсантъ». № 203. 6 ноября 2018. С. 3. 
Цель данного исследования заключается в выявлении факторов, связанных с дифференциацией запроса на поддержку и содействие государства среди населения в современном российском обществе в таких сферах, как (а) обеспечение занятости и работы, (б) социальное инвестирование, понимаемое через помощь государства в сфере образования и здоровья, а также (в) запрос на материальную поддержку, то есть запрос на прямую дистрибутивную политику. Помимо прочего, данное исследование позволяет провести сравнение с теми, кто, по их собственному признанию, не нуждается в помощи государства в решении каких бы то ни было жизненных проблем.

\section{Запрос населения на содействие государства: интересы, потребности, ценности}

Теоретический анализ запросов населения к содействию государства во многом основан на изучении отношения населения к политике всеобщего благосостояния ${ }^{4}$. Исследователи сходятся во мнении, что механизмы этих запросов делятся на две большие группы: (1) собственные интересы населения [Blekesaune, Quadagno 2003; Knijn, van Oorschot 2008] и (2) ценностно-нормативные установки [Blekesaune 2013; Edlund 2006; Hasenfeld, RaVerty 1989; Groskind 1994; Morten, Joeger 2006]. Разумеется, оба механизма дополняются информацией об условиях социализации, особенностях национальной культуры, проявляемых в действующей социальной политике, текущей конфигурацией социальной сферы и т.д. [Blekesaune 2013; Chung, Meuleman 2017; Chung, Taylor-Gooby, Leruth 2018; Kootstra, Roosma 2018 и др.].

Значимость индивидуальных интересов [Здравомыслов 1986] в вопросе восприятия политики всеобщего благосостояния и отдельных ее механизмов рассматриваются в различных аспектах. Интересы женщин традиционно оцениваются через их потребности в детских образовательных и воспитательных учреждениях; интересы профессионалов (особенно в странах с либеральным режимом всеобщего благосостояния) опосредуются уровнем стабильности и защищенности их позиций на рынке труда, возможностями профессиональной реализации, а также трудоустройства в соответствии со своим человеческим капиталом [Iversen, Soskice 2001; Rehm 2011; Edlund 1999; Svallfors 1997; Andreb, Heien 2001; Bean, Papadakis 1998; Forma 1999].

До недавнего времени доход, социально-экономический статус и обеспеченность ресурсами (прежде всего материальными благами) анализировались в линейном ключе. В 1990-х гг. население с относительно низким доходом рассматривалось как основной субъект запроса на обеспечение приемлемого уровня жизни [Edlund 1999; Cook, Barrett 1992]. Другими словами, традиционно предполагалось, что при прочих равных с ростом дохода запрос на редистрибутивную политику и материальную поддержку должен снижаться, однако последние работы выявили более сложную природу этой взаимосвязи. Так, авторы [Dimick, Rueda, Stegmueller 2017] на примере США подтверждают классическую политэкономическую гипотезу Мелзера-Ричарда [Meltzer, Richard 1981] о том, что с ростом неравенства

\footnotetext{
4 Более подробно обзор литературы запросам населения на содействие государства изложен в работе [Аникин,
} Лежнина, Мареева, Слободенюк 2019]. 
запросы на политику перераспределения повышаются [Finseraas 2009], причем этот эффект с ростом дохода (известен как эффект «альтруизма богатых») становится сильнее. Скорее всего, такая поддержка обусловлена тем, что высокие неравенства воспринимаются как несправедливые. В России уровень несправедливых неравенств, выражающихся в устойчивом опережающем росте доходов и благосостояния верхнего 1\% населения [Alvaredo, Chancel, Piketty, Saez, Zucman 2017], является запредельно высоким. Более того, в России дистанция между медианным классом и богатыми намного больше, чем между медианной группой и бедными [Тихонова, Лежнина, Мареева, Аникин, Каравай, Слободенюк 2018], что также объясняет, почему (гипотетически) с ростом дохода россияне могут поддерживать перераспределительную политику [Lupu, Pontusson 2011].

Говоря о располагаемых ресурсах, не стоит забывать и о нематериальных активах: например, о социальном капитале, благодаря которому индивиды способны находить решение целого спектра жизненных проблем - от трудоустройства до получения материальной помощи. Наиболее убедительная гипотеза в этой связи состоит в том, что вероятность запроса на содействие государства значимо ниже у россиян, которые могут решить соответствующие проблемы за счет имеющихся у них связей и социальных контактов.

Что касается линии ценностно-нормативных факторов, определяющих запросы населения к политике всеобщего благосостояния, то здесь следует привести работы, фокусирующиеся на вопросах экономического эгалитаризма или перераспределения [Achterberg, Houtman, Derks 2011; Blekaesaune, Quadagno 2003; Dimick, Rueda, Stegmueller 2017; Luo 1998], а также на различных аспектах восприятия модели государства всеобщего благосостояния [Andreß, Heien 2001; Blekesaune, Quadagno 2003; Campbell 2012; Chung, Filipovič, Rakar 2018; Finseraas 2009; Gingrich, Ansell 2012; Jeeger 2006; Joeger 2009; Mettler, Soss 2004; Svallfors 1997; Svallfors 2004; Svallfors 2010; Svallfors 2012]. Опыт изучения запросов населения к государственной социальной политике в транзитных обществах [Mason, Kluegel, Wegener 1995; Domanski, Heyns 1995; Salmina 2014; Аникин 2006; Салмина 2012] приковывает внимание к гипотезе о роли социокультурной модернизации, центральным элементом которой является проблема формирования определенного типа мышления, характеризующегося внутренним локус-контролем, установками на индивидуальную ответственность, ориентацией на равенство шансов, саморазвитие и т.д. [Аникин, Лежнина, Тихонова, Горюнова 2007; Тихонова 2012; Тихонова 2018]. В этой связи крайне важной задачей становится оценка относительного вклада ценностно-нормативных факторов, связанных с внутренним/внешним локус-контролем, готовностью рассчитывать только на себя или на помощь извне, а также установки на равенство шансов или равенство доходов.

\section{Методология исследования и эмпирическая база}

Эмпирической базой дальнейшего анализа выступают данные восьмой волны мониторингового исследования Института социологии ФНИСЦ РАН «Динамика социальной трансформации современной России в социально-экономическом, политическом, социокультурном и этнорелигиозном контекстах». Восьмая волна 
проведена в апреле 2018 г. по общероссийской двухступенчатой квотной выборке, объем выборки составил 4000 респондентов от 18 лет и старше, представляющих основные социально-профессиональные группы населения, проживающих во всех территориально-экономических районах страны согласно районированию ФСГС РФ и репрезентирующих их население по полу, возрасту и типам поселений.

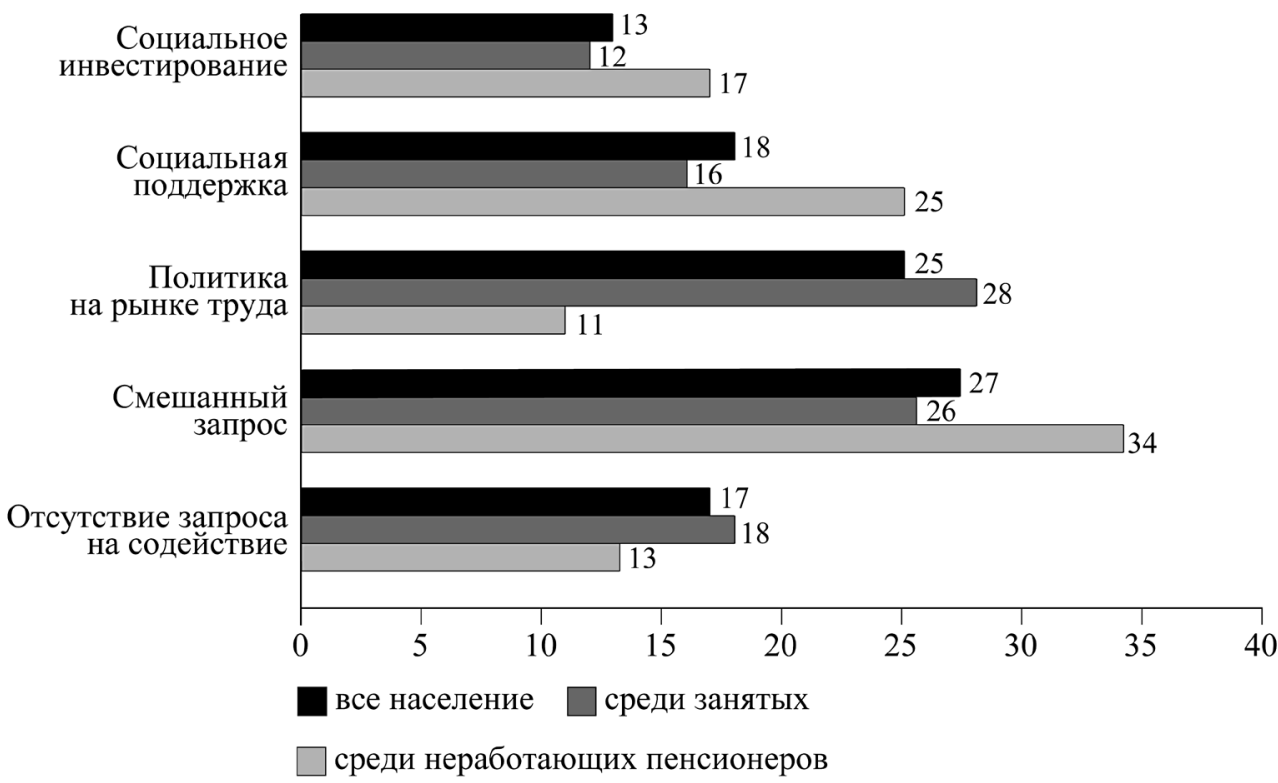

Рисунок 1. Различные типы запросов на содействие государства, \%

Для выделения различных типов запросов на государственную поддержку в зависимости от конкретных жизненных обстоятельств задавался вопрос о необходимом государственном содействии в следующей формулировке: «В решении каких проблем Вашей семьи Вам в наибольшей степени требуется государственная поддержка и содействие?» ${ }^{5}$ (допускалось до трех вариантов ответа). В соответствии с предложениями Дж. Гарритцмана и его коллег [Garritzmann, Busemeyer, Neimanns 2018] на основе ответов на данный вопрос нами были выделены следующие оси запросов на содействие государства: социальное инвестирование (получение необходимого образования и квалификации + решение проблем с необходимой медицинской помощью), социальная поддержка 6

\footnotetext{
5 Еще раз подчеркнем, что в данном случае мы хотели бы сосредоточиться на конкретных запросах россиян на содействие государства в их собственной ситуации, поэтому для моделирования был использован только этот вопрос, в то время как переменные, отражающие нормативные представления о роли государства в целом, включались как независимые факторы при построении расширенных моделей.

6 Логика как материальной помощи, так и обеспечения жильем в рамках мер социальной политики связана с реализацией ее гуманитарной функции, поэтому для простоты восприятия результатов мы будем называть этот тип запроса запросом на социальную поддержку, понимая условность этого названия.
} 
(обеспечение жильем + материальная поддержка), политика на рынке труда (трудоустройство + обеспечение справедливой оплаты труда). Распространенность различных типов запросов на содействие государства, согласно предложенной группировке, представлена на рисунке $1^{7}$.

\section{Факторы формирования различных типов запросов на государственное содействие}

Какова же природа существующих осей запросов? Для ответа на этот вопрос нами был проведен эконометрический анализ запросов на содействие государства в реальной жизненной ситуации, в котором за основу был взят набор переменных, аналогичных рассмотренным в [Garritzmann, Busemeyer, Neimanns 2018] демографическим и социально-экономическим характеристикам. В анализ были включены две переменные, представляющие базовое измерение ценностей рыночной экономики и классического либерализма. Обе переменные представляют собой пары ценностных суждений. Первое суждение характеризует респондентов, которые «могут сами обеспечить себя и свою семью и не нуждаются в поддержке со стороны государства» (установки на индивидуализм), альтернативная ему точка зрения фиксирует ярко выраженную патерналистскую ориентацию - «без поддержки со стороны государства мне и моей семье не выжить» (установки на патернализм), которая использовалась в качестве категории сравнения. Вторая ценностная пара представляет собой также два альтернативных суждения относительно природы (не)равенства ${ }^{8}$. Одно касается «равенства возможностей», которое оценивается «важнее, чем равенство доходов и условий жизни для проявления способностей каждого человека». Другое, альтернативное ему, соответственно постулирует, что «равенство доходов, положения и условий жизни каждого человека важнее, чем равенство возможностей для проявления способностей» (данное суждение выступало в качестве категории сравнения).

\section{Влияние демографии}

В целом же следует отметить, что эконометрическое моделирование в соответствии со стратегией [Garritzmann, Busemeyer, Neimanns 2018] не выявило универсальных факторов, которые бы оказались значимыми для всех типов запросов, помимо дохода (таблииа 1). Говоря о демографии, надо отметить, что в России действуют те же механизмы, что и на Западе. Как и в некоторых европейских странах, женщины в постсоветской России в большей степени представлены на рабочих местах, предполагающих рутинный и низкооплачиваемый нефизический труд [Гимпельсон, Капелюшников, Шарунина 2018; Klimova, Ross 2012]. Такие рабочие места есть

\footnotetext{
7 Подробное описание данных категорий можно проследить в работе [Аникин, Лежнина, Мареева, Слободенюк 2019].

8 Имеется в виду классическое разделение на (не)равенство возможностей и (не)равенство результатов (см. подробно: [Аткинсон 2018]).
} 
всегда, их много, и женщинам на них может быть «удобно» работать, поскольку такая занятость позволяет им заниматься семьей. В итоге проблемы здоровья и образования членов домохозяйства традиционно относятся к сфере ответственности женщин, которые, как видно из таблицы 1, гораздо активнее мужчин предъявляют запрос на государственное содействие в областях социального инвестирования и материальной поддержки, выражающейся в усилении трансфертных функций государства. К этому необходимо добавить, что женщины чаще встречаются в старших возрастных когортах, которые, как известно, предъявляют активный спрос на медицину.

Говоря о возрастных когортах, нужно уточнить, что неработающие россияне пенсионного возраста статистически реже поддерживают идею содействия государства в сфере занятости в силу низкой актуальности лично для них этой сферы, голосуя за другие приоритеты, что существенно выделяет их на фоне остальных представителей среднего и старшего поколения (от 30 лет и выше). Молодежь в сою очередь больше других возрастных когорт нуждается в содействии государства на рынке труда, что является скрытым отражением их более неопределенного положения, которое набирает масштабы не только в России, но и за рубежом [Dwyer, Gorshkov, Modi, Chunling Li, Mapadimeng 2018]. И это может стать достаточно серьезной проблемой в будущем, особенно в условиях взятого властью курса на минимизацию своего участия в рассматриваемых вопросах, поскольку этот курс нарушает статус-кво вчерашней «симфонии» народа и власти и, как следствие, снижает доверие у населения ко всем институтам власти и элите, включая президента, до критически низких показателей 9 .

\section{«Альтруизм богатых» и их инвестищионное бремя}

Наши расчеты показывают, что при прочих равных удвоение среднемесячных доходов российских домохозяйств может привести к 20-процентному снижению вероятности запросов россиян на государственное вмешательство в политику занятости (что однозначно демонстрирует основную причину этого запроса занятость на «плохих» рабочих местах с низкой оплатой труда) и увеличивает на $36 \%$ вероятность отказа от государственного вмешательства в принципе (что указывает на наличие в российском обществе резерва на увеличение этой группы), при этом максимальная вероятность эффекта «альтруизма богатых» в последнем случае не превышает 0,3. В двух других случаях повышение дохода (которое может рассматриваться как грубая аппроксимация распределительных мер социальной политики) не только не решает проблему, но и усиливает потребность в государственном вмешательстве еще больше. Так, из таблицы 1 видно, что чем выше доход у этих россиян, тем больше они чувствуют, что нуждаются в социальной поддержке: двукратный рост среднемесячных доходов домохозяйств этой группы россиян приведет к 28-процентному повышению вероятности запросов населения на перераспределение.

9 См. соответствующие данные опроса Левады-Центра: Одобрение институтов власти (2018) // Левада-Центр. 24 октября 2018 // https:/www.levada.ru/2018/10/24/odobrenie-institutov-vlasti-6/ 
Таблица 1. Эконометрическое моделирование факторов, определяющих запросы на содействие государства в различных сферах, скорректированные на интегральный набор переменных

\begin{tabular}{|c|c|c|c|c|}
\hline & (1) & (2) & (3) & (4) \\
\hline & $\begin{array}{c}\text { Политика } \\
\text { на рынке труда }\end{array}$ & $\begin{array}{c}\text { Социальное } \\
\text { инвестирование }\end{array}$ & $\begin{array}{c}\text { Социальная } \\
\text { поддержка }\end{array}$ & $\begin{array}{c}\text { Нет запроса } \\
\text { на содействие }\end{array}$ \\
\hline Мужской пол & $\begin{array}{c}0.0953 \\
(0.0915) \\
\end{array}$ & $\begin{array}{c}-0.268 * * \\
(0.110) \\
\end{array}$ & $\begin{array}{c}-0.245^{* *} \\
(0.104) \\
\end{array}$ & $\begin{array}{c}0.381^{* * * *} \\
(0.118)\end{array}$ \\
\hline \multicolumn{5}{|l|}{ Возрастные когорты (31-40 - к.с.) } \\
\hline $18-30$ & $\begin{array}{c}0.319 * * * \\
(0.121)\end{array}$ & $\begin{array}{c}-0.0459 \\
(0.176)\end{array}$ & $\begin{array}{l}-0.0293 \\
(0.149)\end{array}$ & $\begin{array}{c}-0.407 * * \\
(0.178)\end{array}$ \\
\hline $41-50$ & $\begin{array}{c}0.130 \\
(0.119)\end{array}$ & $\begin{array}{c}0.243 \\
(0.162)\end{array}$ & $\begin{array}{c}-0.510 * * * \\
(0.156)\end{array}$ & $\begin{array}{l}-0.256 \\
(0.159)\end{array}$ \\
\hline $51-60$ & $\begin{array}{l}-0.105 \\
(0.150)\end{array}$ & $\begin{array}{c}0.121 \\
(0.189)\end{array}$ & $\begin{array}{c}-0.393 * * \\
(0.178)\end{array}$ & $\begin{array}{l}0.394 * * \\
(0.196)\end{array}$ \\
\hline > 60 неработающие & $\begin{array}{c}-0.985^{* * *} \\
(0.229) \\
\end{array}$ & $\begin{array}{l}-0.191 \\
(0.249) \\
\end{array}$ & $\begin{array}{l}0.0676 \\
(0.254) \\
\end{array}$ & $\begin{array}{l}-0.0238 \\
(0.294) \\
\end{array}$ \\
\hline$>60$ работающие & $\begin{array}{l}-0.386 \\
(0.293) \\
\end{array}$ & $\begin{array}{c}0.346 \\
(0.329) \\
\end{array}$ & $\begin{array}{c}-0.902 * * \\
(0.401)\end{array}$ & $\begin{array}{l}-0.159 \\
(0.361)\end{array}$ \\
\hline \multicolumn{5}{|c|}{ Уровень образования (магистратура и выше - к.с.) } \\
\hline Начальное & $\begin{array}{c}0.117 \\
(0.688)\end{array}$ & & $\begin{array}{l}-0.924 \\
(0.716)\end{array}$ & $\begin{array}{l}0.900 \\
(0.556)\end{array}$ \\
\hline Незаконченное среднее общее & $\begin{array}{c}0.264 \\
(0.425) \\
\end{array}$ & $\begin{array}{c}-1.521 * * \\
(0.604)\end{array}$ & $\begin{array}{c}0.590 \\
(0.433)\end{array}$ & $\begin{array}{l}0.0417 \\
(0.546)\end{array}$ \\
\hline Среднее общее & $\begin{array}{l}0.602 * \\
(0.349) \\
\end{array}$ & $\begin{array}{l}-0.580 \\
(0.356) \\
\end{array}$ & $\begin{array}{l}-0.0661 \\
(0.379) \\
\end{array}$ & $\begin{array}{c}0.380 \\
(0.386) \\
\end{array}$ \\
\hline Среднее специальное & $\begin{array}{c}0.336 \\
(0.338) \\
\end{array}$ & $\begin{array}{l}-0.0990 \\
(0.323) \\
\end{array}$ & $\begin{array}{l}-0.0581 \\
(0.360) \\
\end{array}$ & $\begin{array}{c}0.298 \\
(0.360) \\
\end{array}$ \\
\hline Незаконченное высшее & $\begin{array}{c}0.440 \\
(0.360) \\
\end{array}$ & $\begin{array}{l}-0.223 \\
(0.365) \\
\end{array}$ & $\begin{array}{c}0.161 \\
(0.400) \\
\end{array}$ & $\begin{array}{c}-0.00968 \\
(0.414) \\
\end{array}$ \\
\hline Высшее (гуманитарное) & $\begin{array}{c}0.167 \\
(0.321) \\
\end{array}$ & $\begin{array}{l}-0.480 \\
(0.307) \\
\end{array}$ & $\begin{array}{c}0.225 \\
(0.352) \\
\end{array}$ & $\begin{array}{l}0.0702 \\
(0.342) \\
\end{array}$ \\
\hline $\begin{array}{l}\text { Высшее (техническое } \\
\text { и естественно-научное) }\end{array}$ & $\begin{array}{l}0.0717 \\
(0.329) \\
\end{array}$ & $\begin{array}{l}-0.301 \\
(0.310) \\
\end{array}$ & $\begin{array}{c}0.209 \\
(0.356) \\
\end{array}$ & $\begin{array}{c}0.335 \\
(0.342) \\
\end{array}$ \\
\hline Доход домохозяйства (логарифм) & $\begin{array}{c}-0.314 * * * \\
(0.0838) \\
\end{array}$ & $\begin{array}{c}0.362 * * * \\
(0.103) \\
\end{array}$ & $\begin{array}{c}0.243^{* *} \\
(0.108) \\
\end{array}$ & $\begin{array}{c}0.442 * * * \\
(0.128) \\
\end{array}$ \\
\hline Несовершеннолетние дети & $\begin{array}{c}-0.389 * * * \\
(0.111) \\
\end{array}$ & $\begin{array}{l}0.211^{*} \\
(0.122) \\
\end{array}$ & $\begin{array}{c}0.000593 \\
(0.121) \\
\end{array}$ & $\begin{array}{l}-0.0124 \\
(0.134) \\
\end{array}$ \\
\hline \multicolumn{5}{|l|}{ Социальные установки } \\
\hline $\begin{array}{l}\text { Установки на индивидуализм vs } \\
\text { патернализм (к.с.) }\end{array}$ & $\begin{array}{l}-0.0831 \\
(0.0897) \\
\end{array}$ & $\begin{array}{r}-0.0325 \\
(0.119) \\
\end{array}$ & $\begin{array}{c}-0.616^{* * *} \\
(0.110) \\
\end{array}$ & $\begin{array}{c}1.763 * * * \\
(0.143) \\
\end{array}$ \\
\hline $\begin{array}{l}\text { Равенство возможностей vs } \\
\text { равенство доходов (к.с.) }\end{array}$ & $\begin{array}{c}0.274 * * * \\
(0.0854) \\
\end{array}$ & $\begin{array}{c}0.170 \\
(0.111) \\
\end{array}$ & $\begin{array}{c}-0.248 * * * \\
(0.0957)\end{array}$ & $\begin{array}{l}-0.111 \\
(0.119) \\
\end{array}$ \\
\hline Константа (средний уровень) & $\begin{array}{c}0.901 \\
(0.883) \\
\end{array}$ & $\begin{array}{c}-5.344 * * * \\
(1.087) \\
\end{array}$ & $\begin{array}{c}-3.696 * * * \\
(1.209) \\
\end{array}$ & $\begin{array}{c}-5.183 * * * \\
(1.413) \\
\end{array}$ \\
\hline Количество наблюдений & 3,672 & 3,648 & 3,672 & 3,672 \\
\hline
\end{tabular}

Примечание. В таблице представлены оценки логит-коэффициентов логистических моделей. В скобках указаны робастные стандартные ошибки: *** $\mathrm{p}<0.01, * * \mathrm{p}<0.05, * \mathrm{p}<0.1$. Сокращение «к.с.» обозначает категорию сравнения, по отношению к которой необходимо интерпретировать частные эффекты категориальных переменных. В таблице 1 представлены только основные эффекты, соответствующие рассмотренным в работе Дж. Гарритцмана и его коллег признакам. Полный набор переменных, включающий эффекты интегрального набора переменных (объективных и субъективных факторов), которые использовались для контроля базовых моделей, представлен в Приложении Б. Показатели статистического качества оцененных моделей представлены в Приложении $A$. 
Данный эффект «альтруизма богатых» в России не ограничивается лишь установками на перераспределение, но и затрагивает сферу человеческого капитала. Однако что касается последнего, то дело вовсе не в «альтруизме», а, скорее, в уходе государства из сферы инвестиций в качественный человеческий капитал, в результате чего населению приходится решать эти задачи на индивидуальном уровне. Расходы на образование и медицину являются эластичными по доходу, увеличиваясь по мере роста бюджета домохозяйства, вследствие чего обеспеченные россияне могут испытывать сравнительно большую потребность переложить свои расходы на человеческий капитал на плечи государства, чем низкодоходные граждане.

\section{Эффект занятости}

По сравнению с неработающими россиянами все наемные работники (хотя и с разной интенсивностью) высказываются в пользу модели, при которой государство содействует занятости, за исключением управленцев (Приложение Б), которые, видимо, не испытывают острой необходимости в помощи государства, что объясняется их более устойчивой позицией на рынке труда. На наш взгляд, это крайне значимый результат, который показывает, что политика полной занятости, проводимая российскими властями последние 20 лет, является в целом легитимной и пользуется поддержкой широких слоев занятого населения страны. С другой стороны, это может свидетельствовать и о наличии серьезных проблем в этой сфере, которые приводят к восприятию неравенств в доступе к хорошим рабочим местам и, соответственно, заработных платах как нелегитимных [Аникин (1) 2018; Аникин (2) 2018]. Возможно, поэтому наемные работники в массе своей склонны «голосовать» за вмешательство государства в обеспечение справедливой оплаты труда. Так, из Приложения Б видно, что при оценке оплаты своего собственного труда как несправедливой повышается вероятность выбора индивидом модели государственного содействия в области занятости и снижается вероятность отказа от государственной помощи в сфере социального инвестирования. Более того, вероятность запроса на содействие государства в сфере занятости статистически значимо возрастает, если у человека был опыт длительной безработицы. Эти результаты подтверждают, что россияне, ища поддержки у государства, говорят о реальных нуждах, и политика равенства возможностей будет легитимным инструментом удовлетворения этих потребностей.

\section{Комплементарная роль сощиального капитала}

Компенсируются ли эти запросы россиян их социальным капиталом ${ }^{10}$ ? Вопреки нашему предположению, социальный капитал не компенсирует нужду в государственном

\footnotetext{
10 Этот фактор был операционализирован через наличие возможности привлечь свои социальные контакты для получения реальной помощи в различных вопросах, связанных с выделенными типами запросов (в частности, устройство на хорошую работу, решение жилищной проблемы, возможность взять в долг крупную сумму)
} 
содействии на рынке труда, а, скорее, дополняет его. Другими словами, государственное содействие занятости и решение этого вопроса за счет социальных связей - это процессы, представленные в общественном мнении как комплементарные, и их противопоставление не принесет желаемых результатов. Как видно из Приложения $Б$, для модели «Политика на рынке труда» наличие связей, которые помогают найти хорошую работу, положительно связано с вероятностью «голосования» за эту модель. Тем не менее эффект социального капитала не является универсальным для моделирования запросов в целом. Мы обнаруживаем существенное ухудшение модели «Социальное инвестирование», когда добавляем какие-либо из измерений социального капитала. Таким образом, запросы на содействие государства в области социального инвестирования никак не связаны с наличием социального капитала в этой области, что еще раз подтверждает невозможность полного перекладывания этих задач государством на плечи россиян и социальные ресурсы их домохозяйств.

\section{Компенсирующая роль цеенностей}

Немаловажным компенсирующим эффектом служат ценностно-нормативные установки россиян, однако значимость и вес субъективных факторов имеют существенное значение лишь для тех моделей, в которых роль институциональных факторов ослаблена (запросы в сфере социальной поддержки - установки на патернализм и равенство доходов), а также в модели государственного эскапизма (установки на индивидуализм). Например, установки на индивидуализм и собственные возможности при прочих равных увеличивают вероятность того, что индивид вообще не будет просить государственной поддержки, на 17,3\% по сравнению с теми, кому, по их собственному признанию, «без помощи государства не выжить».

Причины этого кроются в том, что россияне, нуждающиеся в помощи государства в области материального обеспечения, фактически раздавлены «неравенствами результатов» [Аткинсон 2018] - проблемой низких заработных плат и недоступности жилья. Формирование патерналистских ожиданий и установок на перераспределение является своего рода ловушкой неравенства результатов, которая со временем может стать для этих россиян объективной реальностью. Получается, что проблема низких доходов и нерешенных жилищных проблем становится миной замедленного действия, способной блокировать чувство ответственности россиян за свое будущее даже при условии повышении их дохода.

Таким образом, массовый рост доходов, наблюдавшийся в России с начала 2000-х гг. и сокративший тем самым бедное население страны вдвое, на самом деле мог не только не гарантировать снижение запросов к государственному содействию в области социального обеспечения, но и усилить их в силу возросшего неравенства между медианным классом и сверхбогатыми. С другой стороны, рост благосостояния россиян мог способствовать снижению бедности и росту внутреннего локус-контроля и тем самым ослаблению запроса на государственную помощь в принципе. Таким образом, «эффект дохода» носит сложный характер: если «альтруизм богатых» опосредуется высокими неравенствами, в том числе немонетарного плана, то обособленность богатых от государственной помощи зиждется на их психологической и финансово-экономической независимости от власти. 


\section{Заключение}

Анализ факторов, связанных с дифференциацией запросов населения к государству, показал, что личные интересы по большей мере определяют ожидания населения, нежели социальные установки, хотя объективная природа установок в долгосрочном периоде также не должна игнорироваться. Так, запросы на перераспределение связаны с установками на патернализм и равенство доходов, в то время как в помощи государства в большей степени не нуждаются обладатели внутреннего локус-контроля и, что важно, отрицающие государство как агента, способного решить их проблемы. При этом меры, нацеленные на повышение уровня доходов российского населения, помогают снизить эти запросы россиян лишь частично - в основном среди обладателей установок на индивидуализм, то есть внутренне готовых и, главное, способных взять ответственность за себя и свою семью. Причем чем выше неравенство в стране, тем менее выражен будет этот эффект даже среди «индивидуалистов».

Это происходит из-за того, что в странах с либеральным режимом государства всеобщего благосостояния, в которых наблюдается высокое неравенство, более высокий уровень доходов приводит к более высокой поддержке перераспределительной политики. В нашей работе не раз отмечалось, что этот феном был назван «альтруизмом богатых» [Dimick, Rueda, Stegmueller 2017]. Как показали результаты нашего исследования, для России он также характерен. Таким образом, крайне высокое неравенство результатов, которое проявляется в России во внутриорганизационных, межотраслевых и межрегиональных разрывах заработных плат, становится если не основным, то крайне значимым фундаментом поддержки стейтистских установок россиян в сфере перераспределения.

Однако это не означает, что политика борьбы с неравенством результатов должна превалировать, к чему сейчас тяготеет повестка российских властей. Главное, должна решаться проблема неравенства жизненных шансов, которую подавляющее большинство россиян просто не в состоянии решить собственными силами. В целях достижения более эффективных результатов действия государства должны быть приоритезированы, и в первую очередь должны реализоваться запросы россиян на государственное участие в политике занятости; проблемы социальных инвестиций будут решаться по мере выравнивания неравенств в доступе к хорошим рабочим местам и достойной оплате квалифицированного труда. И лишь на третьем месте должна стоять задача выравнивания неравенства результатов, направленная на удовлетворение запросов почти пятой части населения страны к государственному содействию в области материальной обеспеченности. При этом следует учитывать, что все три комплекса мер во многом нацелены на разные категории и группы россиян.

\section{Литература}

Авраамова Е.М. (2006) О пространстве возможностей реформирования социальной сферы // Общественные науки и современность. № 3. С. 18-22. 
Аникин В.А. (2006) Жизненные проблемы россиян и их запросы к социальной политике // Социологические исследования. № 12. С. 15-21.

Аникин В.А. (2016) Кризис и национальное самосознание россиян // Мониторинг общественного мнения: Экономические и социальные перемены. Т. 135. № 5. С. 203-232.

Аникин В.А. (1) (2018) Занятость в посткризисной России: роль поселенческих неравенств // Вестник Института социологии. Т. 27. № 4. С. 44-63.

Аникин В.А. (2) (2018) Человеческий капитал в посткризисной России: состояние и отдача // Журнал институциональных исследований. Т. 10. № 2. С. 90-117.

Аникин В.А., Лежнина Ю.П., Мареева С.В., Слободенюк Е.Д. (2019) Запросы россиян на содействие государства: социальное инвестирование или социальная поддержка? // Мониторинг общественного мнения: Экономические и социальные перемены. № 3. С. 345-366.

Аникин В.А., Лежнина Ю.П., Тихонова Н.Е., Горюнова С.В. (2007) Концепция модернизации в работах классиков социологической мысли второй половины XIX - начала XX века // Социология: методология, методы, математическое моделирование. № 24. C. $102-129$.

Аткинсон Э. (2018) Неравенство: как с ним быть? М.: Дело.

Возьмитель А.А. (2016) Социальное неравенство и его риски в советской и постсоветской России // Власть. № 8. С. 5-13.

Гимпельсон В.Е., Капелюшников Р.И., Шарунина А.В. (2018) Низкооплачиваемые рабочие места на российском рынке труда: есть ли выход и куда он ведет? // Экономический журнал ВШЭ. Т. 22. № 4. С. 489-530.

Горшков М.К., Тихонова Н.Е. (ред.) (2008) Социальные неравенства и социальная политика в современной России. М.: Наука.

Горшков М.К., Тихонова Н.Е. (ред.) (2016) Средний класс в современной России. Опыт многолетних исследований. М.: Весь Мир.

Здравомыслов А.Г. (1986) Потребности. Интересы. Ценности. М.: Политиздат.

Липкин А.И. (2012) Россия между несовременными «приказными» институтами и современной демократической культурой // Мир России. Т. 21. № 4. С. 40-62.

Мареева С.В. (2018) Социальные неравенства и социальная структура современной России в восприятии населения // Вестник Института социологии. Т. 26. № 3. С. 101-120.

Петухов В.В. (2011) Ценностная палитра современного российского общества: «идеологическая каша» или поиск новых смыслов? // Мониторинг общественного мнения: Экономические и социальные перемены. Т. 101. № 1. С. 6-23.

Салмина А. (2012) Социальные запросы россиян к государству: факторы формирования и межстрановые сравнения // Мир России. Т. 21. № 3. С. 133-164.

Тихонова Н.Е. (2006) Оптимальная модель социальной политики в массовых представлениях // Социологические исследования. № 12. С. 9-10.

Тихонова Н.Е. (2011) Динамика нормативно-ценностной системы российского общества: 1995-2010 годы // Общественные науки и современность. № 4. С. 5-19.

Тихонова Н.Е. (2012) Особенности «российских модернистов» и перспективы культурной динамики России. Статья 1 // Общественные науки и современность. № 2. С. 38-52.

Тихонова Н.Е. (2013) Социальный либерализм: есть ли альтернативы? // Общественные науки и современность. № 2. С. 32-44.

Тихонова Н.Е. (2014) Социальная структура России: теории и реальность. М.: Новый хронограф.

Тихонова Н.Е. (2018) Соотношение интересов государства и прав человека в глазах россиян: эмпирический анализ // Полис. Политические исследования. № 5. С. 134-149.

Тихонова Н.Е., Лежнина Ю.П., Мареева С.В., Аникин В.А., Каравай А.В., Слободенюк Е.Д. (2018) Модель доходной стратификации российского общества: динамика, факторы, межстрановые сравнения. М.: Нестор-История.

Шкаратан О.И. (1) (2009) Социально-экономическое неравенство и его воспроизводство в современной России. М.: Олма Медиа Групп.

Шкаратан О.И. (2) (2009) Становление постсоветского неоэтакратизма // Общественные науки и современность. № 1. С. 5-22.

Якобсон Л.И. (2006) Социальная политика: коридоры возможностей // Общественные науки и современность. № 2. С. 52-66. 
Achterberg P., Houtman D., Derks A. (2011) Two of a Kind? An Empirical Investigation of Antiwelfarism and Economic Egalitarianism // Public Opinion Quarterly, vol. 75, no 4, pp. 748-760.

Alvaredo F., Chancel L., Piketty T., Saez E., Zucman G. (2017) Global Inequality Dynamics: New Findings from WID.world // American Economic Review, vol. 107, no 5, pp. 404-409.

Andreß H.-J., Heien T. (2001) Four Worlds of Welfare State Attitudes? A Comparison of Germany, Norway, and the United States // European Sociological Review, vol. 17, no 4, pp. 337-356.

Bean C., Papadakis E. (1993) Popular Support for the Welfare State: A Comparison between Institutional Regimes // Journal of Public Policy, vol. 13, no 5, pp. 415-427.

Blekesaune M. (2013) Economic Strain and Public Support for Redistribution: A Comparative Analysis of 28 European Countries // Journal of Social Policy, vol. 42, no 1, pp. 57-72.

Blekesaune M., Quadagno J. (2003) Public Attitudes toward Welfare State Policies: A Comparative Analysis of 24 Nations // European Sociological Review, vol. 19, no 5, pp. 415-427.

Busemeyer M.R. (2015) Skills and Inequality: The Political Economy of Education and Training Reforms in Western Welfare States, Cambridge; New York: Cambridge University Press.

Busemeyer M.R., Trampusch C. (2011) Review Article: Comparative Political Science and the Study of Education // British Journal of Political Science, vol. 41, no 2, pp. 413-443.

Campbell A.L. (2012) Policy Makes Mass Politics // Annual Review of Political Science, vol. 15. pp. 333-351.

Cappelen A.W., Cappelen C., Kuhnle S., Tungodden B. (2018) How to Retrench the Welfare State: Attitudes in the General Population // Social Policy Administration, vol. 52, no 4, pp. 862-879.

Chung H., Filipovič Hrast M., Rakar T. (2018) The Provision of Care: Whose Responsibility and Why? // Attitudes, Aspirations and Welfare: Social Policy Directions in Uncertain Times (eds. Taylor-Gooby P., Leruth B.), Basingstoke: Palgrave Macmillan, pp. 183-214.

Chung H., Meuleman B. (2017) European Parents'Attitudes towards Public Childcare Provision: The Role of Current Provisions, Interests and Odeologies // European Societies, vol. 19, no 1, pp. 49-68.

Chung H., Taylor-Gooby P., Leruth B. (2018) Political Legitimacy and Welfare State Futures: Introduction // Social Policy Administration, vol. 52, no 4, pp. 835-846.

Cook F.L., Barrett E.J. (1992) Support for the American Welfare State: The Views of Congress and the Public, Columbia University Press, New York.

Dimick M., Rueda D., Stegmueller D. (2017) The Altruistic Rich? Inequality and Other-Regarding Preferences for Redistribution // Quarterly Journal of Political Science, vol. 11, no 4, pp. 385-439. DOI: 10.1561/100.00015099

Domanski H., Heyns B. (1995) Toward a Theory of the Role of the State in Market Transition: From Bargaining to Markets in Post-Communism. European Journal of Sociology // Archives Européennes de Sociologie, vol. 36, no 2, pp. 317-351.

Dwyer T., Gorshkov M., Modi I., Chunling Li, Mapadimeng M.S. (eds.) (2018) Handbook of the Sociology of Youth in BRICS Countries, World Scientific Publishing Co. Pte.Ltd.

Edlund J. (1999) Trust in Government and Welfare Regimes: Attitudes to Redistribution and Financial Cheating in the USA and Norway // European Journal of Political Research, vol. 35, no 3, pp. 341-370.

Edlund J. (2006) Trust in the Capability of the Welfare State and General Welfare State Support: Sweden 1997-2002 //Acta Sociologica, vol. 49, no 4, pp. 395-417.

Finseraas H. (2009) Income Inequality and Demand for Redistribution: A Multilevel Analysis of European Public Opinion // Scandinavian Political Studies, vol. 32, no 1, pp. 94-119.

Forma P. (1997) The Rational Legitimacy of the Welfare State: Popular Support for Ten Income Transfer Schemes in Finland // Policy and Politics, vol. 25, no 3, pp. 235-249.

Garritzmann J.L., Busemeyer M.R., Neimanns E. (2018) Public Demand for Social Investment: New Supporting Coalitions for Welfare State Reform in Western Europe? // Journal of European Public Policy, vol. 25, no 6, pp. 844-861.

Giger N., Nelson M. (2011) The Electoral Consequences of Welfare State Retrenchment: Blame Avoidance or Credit Claiming in the Era of Permanent Austerity? // European Journal of Political Research, vol. 50, no 1, pp. 1-23.

Gingrich J., Ansell B. (2012) Preferences in Context: Micro Preferences, Macro Contexts, and the Demand for Social Policy // Comparative Political Studies, vol. 45, no 12, pp. 1624-1654. 
Greene S.A. (2018) Running to Stand Still: Aggressive Immobility and the Limits of Power in Russia // Post-Soviet Affairs, vol. 34, no 5, pp. 333-347.

Groskind F. (1994) Ideological Influences on Public Support for Assistance to Poor Families // Social Work, vol. 39, no 1, pp. 81-89.

Hasenfeld Y., RaVerty J.A. (1989) The Determinants of Public Attitudes Toward the Welfare State // Social Forces, vol. 67, no, 4, pp. 1027-1048.

Hosmer D., Lemeshow S., Sturdivant R.X. (2013) Applied Logistic Regression (3rd Edition), New York: John Wiley \& Sons.

Iversen T., Soskice D. (2001) An Asset Theory of Social Policy Preferences // American Political Science Review, vol. 95, no 4, pp. 875-893.

Jæger M.M. (2009) United but Divided: Welfare Regimes and the Level and Variance in Public Support for Redistribution // European Sociological Review, vol. 25, no 6, pp. 723-737.

Jæger M.M. (2006) Welfare Regimes and Attitudes towards Redistribution: the Regime Hypothesis Revisited // European Sociological Review, vol. 22, no 2, pp. 157-170.

Jakobi A.P., Martens K., Wolf K.D. (2010) Introduction: A Governance Perspective on Education Policy' // Education in Political Science: Discovering a Neglected Field (eds. Jakobi A.P., Martens K., Wolf K.D.), London; New York: Routledge, pp. 1-20.

Jordan J. (2014) Religious Belief, Religious Denomination, and Preferences for Redistribution: a Comparison across 13 Countries // West European Politics, vol. 37, no 1, pp. 19-41.

Klimova A., Ross R. (2012) Gender-based Occupational Segregation in Russia: an Empirical Study // International Journal of Social Economics, vol. 39, no 7, pp. 474-489.

Knijn T., van Oorschot W. (2008) The Need for and the Societal Legitimacy of Social Investments in Children and Their Families // Journal of Family Issues, vol. 29, no 11, pp. 1520-1542.

Kootstra A., Roosma F. (2018) Changing Public Support for Welfare Sanctioning in Britain and the Netherlands: A Persuasion Experiment // Social Policy and Administration, vol. 52, no 4, pp. 847-861.

Long J.S. (1997) Regression Models for Categorical and Limited Dependent Variables, California: SAGE Publications.

Luo X. (1998) What Affects Attitudes towards Government's Role in Solving Unemployment? A Comparative Study of Great Britain and the United States // International Journal of Public Opinion Research, vol. 10, no 2, pp. 121-144.

Lupu N., Pontusson J. (2011) The Structure of Inequality and the Politics of Redistribution // American Political Science Review, vol. 105, no 2, pp. 316-336.

Mason D.S., Kluegel J., Wegener B. (1995) Social Justice and Political Change: Public Opinion in Capitalist and Post-communist States, New York: A. de Gruyter.

Meltzer A.H., Richard S.F. (1981) A Rational Theory of the Size of Government // Journal of Political Economy, vol. 89, no 5, pp. 914-927.

Mettler S., Soss J. (2004) The Consequences of Public Policy for Democratic Citizenship: Bridging Policy Studies and Mass Politics // Perspectives on Politics, vol. 2, no 1, pp. 55-73.

Rehm P. (2011) Social Policy by Popular Demand // World Politics, vol. 63, no 2, pp. 271-299.

Roosma F., van Oorschot W., Gelissen J. (2014) The Preferred Role and Perceived Performance of the Welfare State: European Welfare Attitudes from a Multidimensional Perspective // Social Science Research, vol. 44, pp. 200-210.

Salmina A. (2014) Social Attitudes towards Welfare Policies in Russia and other European Countries // International Social Work, vol. 57, no 5, pp. 459-469.

Svallfors S. (1997) Worlds of Welfare and Attitudes to Redistribution: A Comparison of Eight Western Nations // European Sociological Review, vol. 13, no 3, pp. 283-304.

Svallfors S. (2004) Class, Attitudes and the Welfare State: Sweden in Comparative Perspective // Social Policy and Administration, vol. 38, no 2, pp. 119-138.

Svallfors S. (2010) Public Attitudes // The Oxford Handbook of the Welfare State (eds. Castles F.G., Leibfried S., Lewis J., Obinger H., Pierson C.), Oxford: Oxford University Press, pp. 241-251.

Svallfors S. (2012) Contested Welfare States: Welfare Attitudes in Europe and beyond, Stanford, CA: Stanford University Press.

van Oorschot W., Meuleman B. (2012) Does Popular Support for Welfare States Depend on Their Outcomes? // Contested Welfare States: Welfare Attitudes in Europe and beyond (ed. Svallfors S.), Stanford, CA: Stanford University Press, pp. 25-57. 


\section{Приложения}

\section{Приложение А. Выборочные показатели качества логистических моделей (BIC')}

\begin{tabular}{|l|c|c|c|c|}
\hline \multirow{2}{*}{ Модели } & $(\mathbf{1})$ & $\mathbf{( 2 )}$ & $\mathbf{( 3 )}$ & (4) \\
\cline { 2 - 5 } & $\begin{array}{c}\text { Политика } \\
\text { на рынке труда }\end{array}$ & $\begin{array}{c}\text { Социальное } \\
\text { инвестирование }\end{array}$ & $\begin{array}{c}\text { Социальная } \\
\text { поддержка }\end{array}$ & $\begin{array}{c}\text { Нет запроса } \\
\text { на содействие }\end{array}$ \\
\hline 1. Базовая модель (БМ) & -108.608 & $\mathbf{6 9 . 9 4 1}$ & -22.350 & -466.988 \\
\hline 2. БМ + Иждивение & $\mathrm{n} / \mathrm{a}$ & $\mathrm{n} / \mathrm{a}$ & -21.184 & $\mathrm{n} / \mathrm{a}$ \\
\hline 3. БМ + Объективные факторы & -71.022 & 90.373 & $\mathbf{- 5 5 . 2 4 0}$ & -671.047 \\
\hline 4. Интегральная модель & -71.628 & 122.185 & -17.905 & $\mathbf{- 6 8 2 . 2 6 7}$ \\
\hline
\end{tabular}

Примечание. Сравниваемые модели являются вложенными по каждому из представленных типов запросов, за исключением запросов на содействие государства в сфере политики занятости. Моделирование с факторами, отвечающими за иждивенческую нагрузку, выполнялось лишь для запросов на государственное содействие в области социальной поддержки. Спецификация регрессионных уравнений интегральной модели включает как объективные, так и субъективные факторы. Общее правило сравнения моделей - чем меньше значение ВIC', тем модель более «качественная» (то есть является более подходящей для описания данных). Более подробно см.: [Hosmer, Lemeshow, Sturdivant 2013; Long 1997]. Сравнивая разницы значений ВIC', мы видим, что интегральная модель не во всех случаях является более предпочтительной со статистической точки зрения. Наилучшие модели с точки зрения принципов статистического моделирования (значений ВIC') выделены жирным шрифтом.

Приложение Б. Эконометрическое моделирование факторов, определяющих запросы на содействие государства в различных сферах, интегральный набор переменных

\begin{tabular}{|c|c|c|c|c|}
\hline & (1) & (2) & (3) & (4) \\
\hline & $\begin{array}{c}\text { Политика } \\
\text { на рынке труда }\end{array}$ & $\begin{array}{c}\text { Социальное } \\
\text { инвестирование }\end{array}$ & $\begin{array}{c}\text { Социальная } \\
\text { поддержка }\end{array}$ & $\begin{array}{l}\text { Нет запроса } \\
\text { на содействие }\end{array}$ \\
\hline Мужской пол & $\begin{array}{c}0.0953 \\
(0.0915)\end{array}$ & \begin{tabular}{|c|}
$-0.268^{* *}$ \\
$(0.110)$ \\
\end{tabular} & $\begin{array}{c}-0.245^{* *} \\
(0.104)\end{array}$ & $\begin{array}{c}0.381 * * * \\
(0.118)\end{array}$ \\
\hline \multicolumn{5}{|c|}{ Возрастные когорты (31-40 - к.с.) } \\
\hline $18-30$ & $\begin{array}{c}0.319 * * * \\
(0.121)\end{array}$ & $\begin{array}{l}-0.0459 \\
(0.176)\end{array}$ & $\begin{array}{l}-0.0293 \\
(0.149)\end{array}$ & $\begin{array}{c}-0.407 * * \\
(0.178)\end{array}$ \\
\hline $41-50$ & $\begin{array}{c}0.130 \\
(0.119) \\
\end{array}$ & $\begin{array}{c}0.243 \\
(0.162) \\
\end{array}$ & $\begin{array}{c}-0.510 * * * \\
(0.156) \\
\end{array}$ & $\begin{array}{l}-0.256 \\
(0.159) \\
\end{array}$ \\
\hline $51-60$ & $\begin{array}{l}-0.105 \\
(0.150)\end{array}$ & $\begin{array}{c}0.121 \\
(0.189)\end{array}$ & $\begin{array}{c}-0.393 * * \\
(0.178)\end{array}$ & $\begin{array}{l}0.394 * * \\
(0.196)\end{array}$ \\
\hline > 60 неработающие & $\begin{array}{c}-0.985^{* * * *} \\
(0.229)\end{array}$ & $\begin{array}{c}-0.191 \\
(0.249)\end{array}$ & $\begin{array}{c}0.0676 \\
(0.254)\end{array}$ & $\begin{array}{c}-0.0238 \\
(0.294)\end{array}$ \\
\hline > 60 работающие & $\begin{array}{l}-0.386 \\
(0.293) \\
\end{array}$ & $\begin{array}{c}0.346 \\
(0.329) \\
\end{array}$ & $\begin{array}{c}-0.902 * * \\
(0.401)\end{array}$ & $\begin{array}{l}-0.159 \\
(0.361) \\
\end{array}$ \\
\hline \multicolumn{5}{|c|}{ Уровень образования (магистратура и выше - к.с.) } \\
\hline Начальное & $\begin{array}{c}0.117 \\
(0.688)\end{array}$ & & $\begin{array}{l}-0.924 \\
(0.716)\end{array}$ & $\begin{array}{c}0.900 \\
(0.556)\end{array}$ \\
\hline $\begin{array}{l}\text { Незаконченное среднее } \\
\text { общее }\end{array}$ & $\begin{array}{c}0.264 \\
(0.425)\end{array}$ & $\begin{array}{l}-1.521 * * \\
(0.604)\end{array}$ & $\begin{array}{c}0.590 \\
(0.433)\end{array}$ & $\begin{array}{l}0.0417 \\
(0.546)\end{array}$ \\
\hline Среднее общее & $\begin{array}{l}0.602 * \\
(0.349)\end{array}$ & $\begin{array}{l}-0.580 \\
(0.356)\end{array}$ & $\begin{array}{l}-0.0661 \\
(0.379)\end{array}$ & $\begin{array}{c}0.380 \\
(0.386)\end{array}$ \\
\hline
\end{tabular}




\begin{tabular}{|c|c|c|c|c|}
\hline Среднее специальное & $\begin{array}{c}0.336 \\
(0.338)\end{array}$ & $\begin{array}{l}-0.0990 \\
(0.323)\end{array}$ & $\begin{array}{l}-0.0581 \\
(0.360)\end{array}$ & $\begin{array}{c}0.298 \\
(0.360)\end{array}$ \\
\hline Незаконченное высшее & $\begin{array}{c}0.440 \\
(0.360)\end{array}$ & $\begin{array}{l}-0.223 \\
(0.365)\end{array}$ & $\begin{array}{c}0.161 \\
(0.400)\end{array}$ & $\begin{array}{c}-0.00968 \\
(0.414)\end{array}$ \\
\hline Высшее (гуманитарное) & $\begin{array}{c}0.167 \\
(0.321)\end{array}$ & $\begin{array}{l}-0.480 \\
(0.307)\end{array}$ & $\begin{array}{c}0.225 \\
(0.352)\end{array}$ & $\begin{array}{l}0.0702 \\
(0.342)\end{array}$ \\
\hline $\begin{array}{l}\text { Высшее (техническое } \\
\text { и естественно-научное) }\end{array}$ & $\begin{array}{l}0.0717 \\
(0.329)\end{array}$ & $\begin{array}{l}-0.301 \\
(0.310)\end{array}$ & $\begin{array}{c}0.209 \\
(0.356)\end{array}$ & $\begin{array}{c}0.335 \\
(0.342)\end{array}$ \\
\hline $\begin{array}{l}\text { Доход домохозяйства } \\
\text { (логарифм) }\end{array}$ & $\begin{array}{l}-0.314 * * * \\
(0.0838)\end{array}$ & $\begin{array}{c}0.362 * * * \\
(0.103)\end{array}$ & $\begin{array}{c}0.243 * * \\
(0.108)\end{array}$ & $\begin{array}{c}0.442 * * * \\
(0.128)\end{array}$ \\
\hline Несовершеннолетние дети & $\begin{array}{c}-0.389 * * * \\
(0.111)\end{array}$ & $\begin{array}{l}0.211^{*} \\
(0.122) \\
\end{array}$ & $\begin{array}{c}0.000593 \\
(0.121)\end{array}$ & $\begin{array}{l}-0.0124 \\
(0.134) \\
\end{array}$ \\
\hline \multicolumn{5}{|l|}{ Социальные установки } \\
\hline $\begin{array}{l}\text { Установки на индивидуа- } \\
\text { лизм vs патернализм (к.с.) }\end{array}$ & $\begin{array}{l}-0.0831 \\
(0.0897)\end{array}$ & $\begin{array}{l}-0.0325 \\
(0.119)\end{array}$ & $\begin{array}{l}-0.616^{* * * *} \\
(0.110)\end{array}$ & $\begin{array}{c}1.763^{* * *} \\
(0.143)\end{array}$ \\
\hline $\begin{array}{l}\text { Равенство возможностей vs } \\
\text { равенство доходов (к.с.) }\end{array}$ & $\begin{array}{l}0.274 * * * \\
(0.0854)\end{array}$ & $\begin{array}{l}0.170 \\
(0.111)\end{array}$ & $\begin{array}{c}-0.248^{* * *} \\
(0.0957)\end{array}$ & $\begin{array}{c}-0.111 \\
(0.119)\end{array}$ \\
\hline $\begin{array}{l}\text { Количество членов } \\
\text { в домохозяйстве }\end{array}$ & $\begin{array}{l}0.100^{* *} \\
(0.0401)\end{array}$ & & & \\
\hline Пенсионеры в домохозяйстве & & & $\begin{array}{c}0.218 \\
(0.134)\end{array}$ & \\
\hline Студенты в домохозяйстве & & & $\begin{array}{c}-0.401 * * \\
(0.179)\end{array}$ & \\
\hline \multicolumn{5}{|c|}{ Профессиональная структура (неработающие - к.с.) } \\
\hline Руководители & $\begin{array}{l}-0.270 \\
(0.218)\end{array}$ & $\begin{array}{l}-0.355 \\
(0.244)\end{array}$ & $\begin{array}{l}-0.0930 \\
(0.258) \\
\end{array}$ & $\begin{array}{c}-0.204 \\
(0.261)\end{array}$ \\
\hline Профессионалы & $\begin{array}{c}0.655^{* * *} \\
(0.197) \\
\end{array}$ & $\begin{array}{c}-0.542 * * \\
(0.242)\end{array}$ & $\begin{array}{l}-0.324 \\
(0.244)\end{array}$ & $\begin{array}{l}-0.382 \\
(0.261)\end{array}$ \\
\hline Служащие & $\begin{array}{l}0.344^{* *} \\
(0.161)\end{array}$ & $\begin{array}{c}-0.679 * * * \\
(0.197) \\
\end{array}$ & $\begin{array}{c}0.275 \\
(0.205) \\
\end{array}$ & $\begin{array}{l}-0.358 \\
(0.235) \\
\end{array}$ \\
\hline Рабочие & $\begin{array}{c}0.723 * * * \\
(0.157)\end{array}$ & $\begin{array}{c}-0.858 * * * \\
(0.206)\end{array}$ & $\begin{array}{l}-0.135 \\
(0.213)\end{array}$ & $\begin{array}{l}-0.415^{*} \\
(0.239)\end{array}$ \\
\hline Опыт длительной безработицы & $\begin{array}{c}-0.237 * * \\
(0.110)\end{array}$ & & & \\
\hline $\begin{array}{l}\text { Источник доходов - } \\
\text { трансферты }\end{array}$ & & & $\begin{array}{l}-0.0107 \\
(0.125)\end{array}$ & $\begin{array}{l}-0.120 \\
(0.153)\end{array}$ \\
\hline Нестабильные доходы & & & $\begin{array}{l}-0.246^{*} \\
(0.134)\end{array}$ & $\begin{array}{c}-0.374 * * \\
(0.157)\end{array}$ \\
\hline \multicolumn{5}{|c|}{ Годовая динамика материального положения (не изменилось - к.с.) } \\
\hline Улучшилось & & & $\begin{array}{c}0.483 * * * \\
(0.155)\end{array}$ & $\begin{array}{c}-0.324 * * \\
(0.153)\end{array}$ \\
\hline Ухудшилось & & & $\begin{array}{l}-0.0368 \\
(0.109) \\
\end{array}$ & $\begin{array}{c}-0.849 * * * \\
(0.150)\end{array}$ \\
\hline \multicolumn{5}{|c|}{ Материально обеспечены, самооценка («хорошо» - к.с.) } \\
\hline Удовлетворительно & & & $\begin{array}{c}0.179 \\
(0.182)\end{array}$ & $\begin{array}{c}-0.682 * * * \\
(0.143)\end{array}$ \\
\hline Плохо & & & $\begin{array}{l}0.0163 \\
(0.219) \\
\end{array}$ & $\begin{array}{c}-1.142 * * * \\
(0.268)\end{array}$ \\
\hline \multicolumn{5}{|c|}{ Жилищные условия, самооценка («хорошо» - к.с.) } \\
\hline Удовлетворительно & & & $\begin{array}{c}0.420 * * * \\
(0.124)\end{array}$ & $\begin{array}{c}-0.771 * * * \\
(0.121)\end{array}$ \\
\hline
\end{tabular}




\begin{tabular}{|c|c|c|c|c|}
\hline Плохо & & & $\begin{array}{c}1.529 * * * \\
(0.161)\end{array}$ & $\begin{array}{c}-1.903 * * * \\
(0.317)\end{array}$ \\
\hline \multicolumn{5}{|c|}{ Состояние здоровья, самооценка («хорошо» - к.с.) } \\
\hline Удовлетворительно & & $\begin{array}{c}0.487 * * * \\
(0.142)\end{array}$ & & \\
\hline Плохо & & $\begin{array}{c}0.741^{* * * *} \\
(0.190)\end{array}$ & & \\
\hline \multicolumn{5}{|c|}{ Возможности медицинской помощи, самооценка («хорошо» - к.с.) } \\
\hline Удовлетворительно & & $\begin{array}{c}0.523 * * * \\
(0.189)\end{array}$ & & \\
\hline Плохо & & $\begin{array}{l}0.493 * * \\
(0.202)\end{array}$ & & \\
\hline $\begin{array}{l}\text { Социальный капитал - } \\
\text { решение жилищной проблемы }\end{array}$ & & & $\begin{array}{l}0.472 * \\
(0.248)\end{array}$ & \\
\hline $\begin{array}{l}\text { Социальный капитал - } \\
\text { возможность взять в долг более } \\
100 \text { тыс. руб. }\end{array}$ & & & $\begin{array}{l}-0.501 * \\
(0.264)\end{array}$ & \\
\hline $\begin{array}{l}\text { Социальный капитал - } \\
\text { устройство на хорошую работу }\end{array}$ & $\begin{array}{l}0.289 * * \\
(0.145)\end{array}$ & & & \\
\hline $\begin{array}{l}\text { Отсутствие социального } \\
\text { капитала }\end{array}$ & & & & $\begin{array}{c}0.146 \\
(0.113)\end{array}$ \\
\hline \multicolumn{5}{|c|}{ Ценностно-нормативные утверждения } \\
\hline \multicolumn{5}{|c|}{$\begin{array}{l}\text { «Люди в России получают достойное вознаграждение за свои интеллектуальные способности } \\
\text { и квалификацию» (Отчасти согласны, отчасти нет - к.с.) }\end{array}$} \\
\hline Согласны & $\begin{array}{l}-0.137 \\
(0.129)\end{array}$ & $\begin{array}{l}-0.114 \\
(0.153)\end{array}$ & $\begin{array}{c}0.150 \\
(0.136)\end{array}$ & $\begin{array}{l}0.0239 \\
(0.145)\end{array}$ \\
\hline Не согласны & $\begin{array}{l}0.207 * * \\
(0.0902)\end{array}$ & $\begin{array}{l}-0.145 \\
(0.115)\end{array}$ & $\begin{array}{l}-0.138 \\
(0.105)\end{array}$ & $\begin{array}{l}-0.440 * * * \\
(0.122)\end{array}$ \\
\hline \multicolumn{5}{|c|}{$\begin{array}{l}\text { «вы лично получаете, учитьввая Вашу квалификацию и тяжесть труда, на своей работе значительно } \\
\text { меньше, чем Вы заслуживаете» (Отчасти согласны, отчасти нет - к.с.) }\end{array}$} \\
\hline Согласны & $\begin{array}{r}0.389 * * * \\
(0.0901)\end{array}$ & $\begin{array}{c}-0.239 * * \\
(0.114)\end{array}$ & $\begin{array}{l}-0.157 \\
(0.102)\end{array}$ & $\begin{array}{c}-0.537 * * * \\
(0.123)\end{array}$ \\
\hline Не согласны & $\begin{array}{r}-0.0555 \\
(0.136)\end{array}$ & $\begin{array}{c}0.219 \\
(0.151)\end{array}$ & $\begin{array}{l}-0.259 \\
(0.158)\end{array}$ & $\begin{array}{c}0.203 \\
(0.151)\end{array}$ \\
\hline \multicolumn{5}{|c|}{$\begin{array}{l}\text { «осударство должно обеспечить каждому получение определенного гарантированного уровня доходов» } \\
\text { (Отчасти согласны, отчасти нет - к.с.) }\end{array}$} \\
\hline Согласны & $\begin{array}{l}0.201 * * \\
(0.0992)\end{array}$ & $\begin{array}{c}-0.173 \\
(0.113)\end{array}$ & $\begin{array}{c}-0.110 \\
(0.108)\end{array}$ & $\begin{array}{c}-0.280^{* *} \\
(0.116)\end{array}$ \\
\hline Не согласны & $\begin{array}{c}0.220 \\
(0.194)\end{array}$ & $\begin{array}{c}-0.116 \\
(0.231)\end{array}$ & $\begin{array}{c}0.0181 \\
(0.232)\end{array}$ & $\begin{array}{l}-0.183 \\
(0.211)\end{array}$ \\
\hline Константа (средний уровень) & $\begin{array}{c}0.901 \\
(0.883) \\
\end{array}$ & $\begin{array}{c}-5.344 * * * \\
(1.087) \\
\end{array}$ & $\begin{array}{c}-3.696^{* * *} \\
(1.209) \\
\end{array}$ & $\begin{array}{c}-5.183 * * * \\
(1.413)\end{array}$ \\
\hline Количество наблюдений & 3,672 & 3,648 & 3,672 & 3,672 \\
\hline
\end{tabular}

Примечание. Здесь и далее в скобках указаны робастные стандартные ошибки: *** $\mathrm{p}<0.01, * * \mathrm{p}<0.05, * \mathrm{p}<0.1$. Сокращение «к.с.» обозначает категорию сравнения, по отношению к которой необходимо интерпретировать частные эффекты категориальных переменных. 


\title{
The Factors behind the Demand of Russians for the State Support
}

\author{
V. ANIKIN*, Yu. LEZHNINA**, S. MAREEVA***, E. SLOBODENYUK****
}

\begin{abstract}
*Vasiliy Anikin - PhD in Economics, PhD in Sociology, Assistant Professor, Senior Research Fellow, National Research University Higher School of Economics. Address: 20, Myasnitskaya St., Moscow, 101000, Russian Federation; Leading Research Fellow, Institute of Sociology of the Federal Center of Theoretical and Applied Sociology of the Russian Academy of Sciences. Address: bld. 5, 24/35, Krzhizhanovskogo St., Moscow, 117218, Russian Federation. E-mail: vanikin@hse.ru

**Yulia Lezhnina - PhD in Sociology, Assistant Professor, Senior Research Fellow, National Research University Higher School of Economics. Address: 20, Myasnitskaya St., Moscow, 101000, Russian Federation; Senior Research Fellow, Institute of Sociology of the Federal Center of Theoretical and Applied Sociology of the Russian Academy of Sciences. Address: bld. 5, 24/35, Krzhizhanovskogo St., Moscow, 117218, Russian Federation. E-mail: jlezhnina@hse.ru

***Svetlana Mareeva - PhD in Sociology, Director, Center for Stratification Studies, National Research University Higher School of Economics. Address: 20, Myasnitskaya St., Moscow, 101000, Russian Federation; Leading Research Fellow, Institute of Sociology of the Federal Center of Theoretical and Applied Sociology of the Russian Academy of Sciences. Address: bld. 5, 24/35, Krzhizhanovskogo St., Moscow, 117218, Russian Federation. E-mail: smareeva@hse.ru

****Ekaterina Slobodenyuk $-\mathrm{PhD}$ in Sociology, Assistant Professor, Research Fellow, National Research University Higher School of Economics. Address: 20, Myasnitskaya St., Moscow, 101000, Russian Federation; Research Fellow, Institute of Sociology of the Federal Center of Theoretical and Applied Sociology of the Russian Academy of Sciences. Address: bld. 5, 24/35, Krzhizhanovskogo St., Moscow, 117218, Russian Federation. E-mail: eslobodenyuk@hse.ru
\end{abstract}

Citation: Anikin V., Lezhnina Yu., Mareeva S., Slobodenyuk E. (2020) The Factors behind the Demand of Russians for the State Support. Mir Rossii, vol. 29, no 1, pp. 31-52 (in Russian). DOI: 10.17323/1811-038X-2020-29-1-31-52

\section{Abstract}

This paper addresses the underlying nature of the demands of Russians for the welfare state, specifically the demand for state support in the labor market and employment, social investments, and material support. Based on the recent findings from social policy studies, we test four different mechanisms: (a) the demographic features of the population, (b) household incomes and disposable assets, including human and social capital, (c) interests, and (d) locus control and cultural settings. Drawing on data of the allRussian representative Monitoring survey conducted by the Institute of Sociology of the Russian Academy of Sciences in 2018, we argue that people's demands for state support are very complex. In particular, we reveal a paradox in the relative impact of income. On the one hand, the Russian data confirm the hypothesis of 'altruistic reach' developed in recent studies, according to which, in highly unequal societies, higher economic standing is associated with higher demand for redistributive policies. On the other hand, higher economic standing also fosters state escapism of those affluent Russians who do not regard the state as a reliable agent capable of solving their problems. 
Key words: social policy, welfare state, statist society, state and society, social investments, employment policy, material support, modern Russia

\section{References}

Achterberg P., Houtman D., Derks A. (2011) Two of a Kind? An Empirical Investigation of Anti-welfarism and Economic Egalitarianism. Public Opinion Quarterly, vol. 75, no 4, pp. $748-760$.

Alvaredo F., Chancel L., Piketty T., Saez E., Zucman G. (2017) Global Inequality Dynamics: New Findings from WID.world. American Economic Review, vol. 107, no 5, pp. 404-409.

Andreß H.-J., Heien T. (2001) Four Worlds of Welfare State Attitudes? A Comparison of Germany, Norway, and the United States. European Sociological Review, vol. 17, no 4, pp. 337-356.

Anikin V.A. (2006) Zhiznennye problemy rossiyan i ih zaprosy k sotsial'noj politike [Russians' Everyday Problems and Their Social Policy Demands]. Sotsiologicheskie issledovaniya, no 12 , pp. $15-21$.

Anikin V.A. (2016) Krizis i natsional'noe samosoznanie rossiyan [Crisis and Russian National Identity]. The Monitoring of Public Opinion: Economic and Social Changes Journal, vol. 135, no 5, pp. 203-232.

Anikin V.A. (1) (2018) Zanyatost' v postkrizisnoj Rossii: rol' poselencheskikh neravenstv [Employment in Post-crisis Russia: the Role of Between-Settlement Inequalities]. Bulletin of the Institute of Sociology (Vestnik instituta sotziologii), no 27, pp. 44-63.

Anikin V.A. (2) (2018) Chelovecheskij kapital v postkrizisnoj Rossii: sostoyaniye i otdacha [Human Capital in Post-Crisis Russia: the Level and Returns]. Journal of Institutional Studies, vol. 10, no 2, pp. 90-117.

Anikin V., Lezhnina Y., Mareeva S., Slobodenyuk E. (2019) Zaprosy rossiyan na sodejstvie gosudarstva: sotsial'noe investirovanie ili sotsial'naya podderzhka? [The Demands of the Russian Population for State Intervention: Social Investment or Social Support?]. The Monitoring of Public Opinion: Economic and Social Changes Journal, no 3, pp. 345-366.

Anikin V., Lezhnina Y., Tikhonova N., Goryunova S. (2007) Kontseptsiya modernizatsii v rabotakh klassikov sotsiologicheskoj mysli vtoroj poloviny XIX - nachala XX veka [The Concept of Modernization in the Works of Classics of Sociological Thought of the Second Half of the XIX - Early XX Century]. Sotsiologiya: metodologiya, metody, matematicheskoe modelirovanie, no 24, pp. 102-129.

Atkinson A. (2018) Neravenstvo: kak s nim byt'? [Inequality: What Can Be Done?], Moscow: Delo. Avraamova E.M. (2006) O prostranstve vozmozhnostej reformirovaniya sotsial'noj sfery [On the Range of Opportunities for Reforming the Social Sphere]. Social Sciences and Contemporary World, no 3, p. 18-22.

Bean C., Papadakis E. (1993) Popular Support for the Welfare State: A Comparison between Institutional Regimes. Journal of Public Policy, vol. 13, no 5, pp. 415-427.

Blekesaune M. (2013) Economic Strain and Public Support for Redistribution: A Comparative Analysis of 28 European Countries. Journal of Social Policy, vol. 42, no 1, pp. 57-72.

Blekesaune M., Quadagno J. (2003) Public Attitudes toward Welfare State Policies: A Comparative Analysis of 24 Nations. European Sociological Review, vol. 19, no 5, pp. 415-427.

Busemeyer M.R. (2015) Skills and Inequality: The Political Economy of Education and Training Reforms in Western Welfare States, Cambridge; New York: Cambridge University Press.

Busemeyer M.R., Trampusch C. (2011) Review Article: Comparative Political Science and the Study of Education. British Journal of Political Science, vol. 41, no 2, pp. 413-443.

Campbell A.L. (2012) Policy Makes Mass Politics. Annual Review of Political Science, vol. 15. pp. $333-351$.

Cappelen A.W., Cappelen C., Kuhnle S., Tungodden B. (2018) How to Retrench the Welfare State: Attitudes in the General Population. Social Policy Administration, vol. 52, no 4, pp. $862-879$. 
Chung H., Filipovič Hrast M., Rakar T. (2018) The Provision of Care: Whose Responsibility and Why? Attitudes, Aspirations and Welfare: Social Policy Directions in Uncertain Times (eds. Taylor-Gooby P., Leruth B.), Basingstoke: Palgrave Macmillan, pp. 183-214.

Chung H., Meuleman B. (2017) European Parents' Attitudes towards Public Childcare Provision: The Role of Current Provisions, Interests and Odeologies. European Societies, vol. 19, no 1, pp. 49-68.

Chung H., Taylor-Gooby P., Leruth B. (2018) Political Legitimacy and Welfare State Futures: Introduction. Social Policy Administration, vol. 52, no 4, pp. 835-846.

Cook F.L., Barrett E.J. (1992) Support for the American Welfare State: The Views of Congress and the Public, Columbia University Press, New York.

Dimick M., Rueda D., Stegmueller D. (2017) The Altruistic Rich? Inequality and Other-Regarding Preferences for Redistribution. Quarterly Journal of Political Science, vol. 11, no 4, pp. 385-439. DOI: 10.1561/100.00015099

Domanski H., Heyns B. (1995) Toward a Theory of the Role of the State in Market Transition: From Bargaining to Markets in Post-Communism. European Journal of Sociology. Archives Européennes de Sociologie, vol. 36, no 2, pp. 317-351.

Dwyer T., Gorshkov M., Modi I., Chunling Li, Mapadimeng M.S. (eds.) (2018) Handbook of the Sociology of Youth in BRICS Countries, World Scientific Publishing Co. Pte.Ltd.

Edlund J. (1999) Trust in Government and Welfare Regimes: Attitudes to Redistribution and Financial Cheating in the USA and Norway. European Journal of Political Research, vol. 35, no 3, pp. 341-370.

Edlund J. (2006) Trust in the Capability of the Welfare State and General Welfare State Support: Sweden 1997-2002. Acta Sociologica, vol. 49, no 4, pp. 395-417.

Finseraas H. (2009) Income Inequality and Demand for Redistribution: A Multilevel Analysis of European Public Opinion. Scandinavian Political Studies, vol. 32, no 1, pp. 94-119.

Forma P. (1997) The Rational Legitimacy of the Welfare State: Popular Support for Ten Income Transfer Schemes in Finland. Policy and Politics, vol. 25, no 3, pp. 235-249.

Garritzmann J.L., Busemeyer M.R., Neimanns E. (2018) Public Demand for Social Investment: New Supporting Coalitions for Welfare State Reform in Western Europe? Journal of European Public Policy, vol. 25, no 6, pp. 844-861.

Giger N., Nelson M. (2011) The Electoral Consequences of Welfare State Retrenchment: Blame Avoidance or Credit Claiming in the Era of Permanent Austerity? European Journal of Political Research, vol. 50, no 1, pp. 1-23.

Gimpelson V., Kapeliushnikov R., Sharunina A. (2018) Nizkooplachivaemye rabochie mesta na rossijskom rynke truda: est' li vykhod i kuda on vedet? [Low-Paid Jobs in the Russian Labor Market: Is There a Solution and Where Does It Lead to?]. The HSE Economic Journal, vol. 22, no 4, pp. 489-530.

Gingrich J., Ansell B. (2012) Preferences in Context: Micro Preferences, Macro Contexts, and the Demand for Social Policy. Comparative Political Studies, vol. 45, no 12, pp. 1624-1654.

Gorshkov M.K., Tikhonova N.E. (eds.) (2008) Sortsial'nye neravenstva i sotsial'naya politika $v$ sovremennoj Rossii [Social Inequalities and Social Policy in Contemporary Russia], Moscow: Nauka.

Gorshkov M.K., Tikhonova N.E. (eds.) (2016) Srednij klass v sovremennoj Rossii. Opyt mnogoletnikh issledovanij [Middle Class in Modern Russia. The Many Years of Research], Moscow: Ves' Mir.

Greene S.A. (2018) Running to Stand Still: Aggressive Immobility and the Limits of Power in Russia. Post-Soviet Affairs, vol. 34, no 5, pp. 333-347.

Groskind F. (1994) Ideological Influences on Public Support for Assistance to Poor Families. Social Work, vol. 39, no 1, pp. 81-89.

Hasenfeld Y., RaVerty J.A. (1989) The Determinants of Public Attitudes Toward the Welfare State. Social Forces, vol. 67, no, 4, pp. 1027-1048.

Hosmer D., Lemeshow S., Sturdivant R.X. (2013) Applied Logistic Regression (3rd Edition), New York: John Wiley \& Sons.

Iversen T., Soskice D. (2001) An Asset Theory of Social Policy Preferences. American Political Science Review, vol. 95, no 4, pp. 875-893. 
Jæger M.M. (2009) United but Divided: Welfare Regimes and the Level and Variance in Public Support for Redistribution. European Sociological Review, vol. 25, no 6, pp. 723-737.

Jæger M.M. (2006) Welfare Regimes and Attitudes towards Redistribution: the Regime Hypothesis Revisited. European Sociological Review, vol. 22, no 2, pp. 157-170.

Jakobi A.P., Martens K., Wolf K.D. (2010) Introduction: A Governance Perspective on Education Policy'. Education in Political Science: Discovering a Neglected Field (eds. Jakobi A.P., Martens K., Wolf K.D.), London; New York: Routledge, pp. 1-20.

Jakobson L. (2006) Sotsial'naya politika: koridory vozmozhnostej [Social Policy: Corridors of Opportunity]. Social Sciences and Contemporary World, no 2, pp. 52-66.

Jordan J. (2014) Religious Belief, Religious Denomination, and Preferences for Redistribution: a Comparison across 13 Countries. West European Politics, vol. 37, no 1, pp. 19-41.

Klimova A., Ross R. (2012) Gender-based Occupational Segregation in Russia: an Empirical Study. International Journal of Social Economics, vol. 39, no 7, pp. 474-489.

Knijn T., van Oorschot W. (2008) The Need for and the Societal Legitimacy of Social Investments in Children and Their Families. Journal of Family Issues, vol. 29, no 11, pp. 1520-1542.

Kootstra A., Roosma F. (2018) Changing Public Support for Welfare Sanctioning in Britain and the Netherlands: A Persuasion Experiment. Social Policy and Administration, vol. 52, no 4, pp. 847-861.

Lipkin A.I. (2012) Rossiya mezhdu nesovremennymi «prikaznymi» institutami i sovremennoj demokraticheskoj kul'turoj [Russia Between the Non-Modern 'Mandatory' Institutions and the Modern Democratic Culture]. Mir Rossii, vol. 21, no 4, pp. 40-62.

Long J.S. (1997) Regression Models for Categorical and Limited Dependent Variables, California: SAGE Publications.

Luo X. (1998) What Affects Attitudes towards Government's Role in Solving Unemployment? A Comparative Study of Great Britain and the United States. International Journal of Public Opinion Research, vol. 10, no 2, pp. 121-144.

Lupu N., Pontusson J. (2011) The Structure of Inequality and the Politics of Redistribution. American Political Science Review, vol. 105, no 2, pp. 316-336.

Mareeva S.V. (2018) Sotsial'nye neravenstva i sotsial'naya struktura sovremennoj Rossii v vospriyatii naseleniya. [Social Inequalities and the Social Structure of Modern Russia in Public Perceptions]. Bulletin of the Institute of Sociology (Vestnik instituta sotziologii), vol. 26, no 3, pp. 101-120.

Mason D.S., Kluegel J., Wegener B. (1995) Social Justice and Political Change: Public Opinion in Capitalist and Post-communist States, New York: A. de Gruyter.

Meltzer A.H., Richard S.F. (1981) A Rational Theory of the Size of Government. Journal of Political Economy, vol. 89, no 5, pp. 914-927.

Mettler S., Soss J. (2004) The Consequences of Public Policy for Democratic Citizenship: Bridging Policy Studies and Mass Politics. Perspectives on Politics, vol. 2, no 1, pp. 55-73.

PetukhovV.(2011) Tsennostnaya palitra sovremennogo rossijskogo obshchestva: ideologicheskaya kasha ili poisk novykh smyslov? [The Values of the Modern Russian Society: an Ideological Mess or the Search for New Meanings?]. The Monitoring of Public Opinion: Economic and Social Changes Journal, vol. 101, no 1, pp. 6-23.

Rehm P. (2011) Social Policy by Popular Demand. World Politics, vol. 63, no 2, pp. 271-299.

Roosma F., van Oorschot W., Gelissen J. (2014) The Preferred Role and Perceived Performance of the Welfare State: European Welfare Attitudes from a Multidimensional Perspective. Social Science Research, vol. 44, pp. 200-210.

Salmina A. (2012) Sotsial'nye zaprosy rossiyan k gosudarstvu: faktory formirovaniya i mezhstranovye sravne-niya [The Attitudes of Russians Towards the State: the Determinants and Cross-Country Comparisons]. Mir Rossii, vol. 21, no 3, pp. 133-164.

Salmina A. (2014) Social Attitudes towards Welfare Policies in Russia and other European Countries. International Social Work, vol. 57, no 5, pp. 459-469.

Shkaratan O. (1) (2009) Sotsial'no-ekonomicheskoe neravenstvo i ego vosproizvodstvo $v$ sovremennoj Rossii [Socio-economic Inequality and Its Reproduction in Modern Russia], Moscow: Olma Media Grupp.

Shkaratan O. (2) (2009) Stanovlenie postsovetskogo neoetakratizma [The Emergence of the Post-Soviet neo-Etacratism]. Social Sciences and Contemporary World, no 1, pp. 5-22. 
Svallfors S. (1997) Worlds of Welfare and Attitudes to Redistribution: A Comparison of Eight Western Nations. European Sociological Review, vol. 13, no 3, pp. 283-304.

Svallfors S. (2004) Class, Attitudes and the Welfare State: Sweden in Comparative Perspective. Social Policy and Administration, vol. 38, no 2, pp. 119-138.

Svallfors S. (2010) Public Attitudes. The Oxford Handbook of the Welfare State (eds. Castles F.G., Leibfried S., Lewis J., Obinger H., Pierson C.), Oxford: Oxford University Press, pp. 241-251.

Svallfors S. (2012) Contested Welfare States: Welfare Attitudes in Europe and beyond, Stanford, CA: Stanford University Press.

Tikhonova N.E. (2006) Optimal'naya model' sotsial'noj politiki v massovykh predstavleniyakh [The Optimal Model of Social Policy in Mass Expectations]. Sotsiologicheskie issledovaniya, no 12 , pp. 9-10.

Tikhonova N.E. (2011) Dinamika normativno-tsennostnoj sistemy rossijskogo obshchestva: 1995-2010 gody [The Dynamics of the Normative-Value System of the Russian Society (1995-2010)]. Social Sciences and Contemporary World, no 4, pp. 5-19.

Tikhonova N.E. (2012) Osobennosti «rossijskiKh modernistov» i perspektivy kul'turnoj dinamiki Rossii. Stat'ya 1 [The Characteristics of the "Russian Modernists" and the Prospects of the Cultural Dynamics in Russia. Article No.1]. Social Sciences and Contemporary World, no 2, pp. 38-52.

Tikhonova N.E. (2013) Sotsial'nyj liberalizm: est' li al'ternativy? [Social Liberalism: Are There any Alternatives?]. Social Sciences and Contemporary World, no 2, pp. 32-44.

Tikhonova N.E. (2014) Sotsial'naya struktura Rossii: teorii i real'nost' [Social Structure of Russia: Theory and Reality], Moscow: Novyj hronograf.

Tikhonova N.E. (2018) Sootnoshenie interesov gosudarstva i prav cheloveka v glazakh rossiyan: empiricheskij analiz [Balance of State Interests and Human Rights in the Perception of Russians: an Empirical Analysis]. Polis. Politicheskie issledovaniya, no 5, pp. 134-149.

Tikhonova N.E., Lezhnina Yu.P., Mareeva S.V., Anikin V.A., Karavay A.V., Slobodenyuk E.D. (2018) Model' dokhodnoj stratifikatsii rossiyskogo obshchestva: dinamika, faktory, mezhstranovyye sravneniya [The Model of Income Stratification of the Russian Society: Dynamics, Factors, Cross-Country Comparisons], Moscow: Nestor-History.

van Oorschot W., Meuleman B. (2012) Does Popular Support for Welfare States Depend on Their Outcomes? Contested Welfare States: Welfare Attitudes in Europe and beyond (ed. Svallfors S.), Stanford, CA: Stanford University Press, pp. 25-57.

Voz'mitel' A.A. (2016) Sotsial'noe neravenstvo i ego riski v sovetskoj i postsovetskoj Rossii [Social Inequality and Its Risks in Soviet and Post-soviet Russia]. Vlast', no 8, pp. 5-13.

Zdravomyslov A.G. (1986) Potrebnosti. Interesy. Tsennosti [Needs. Interests. Values], Moscow: Politizdat. 